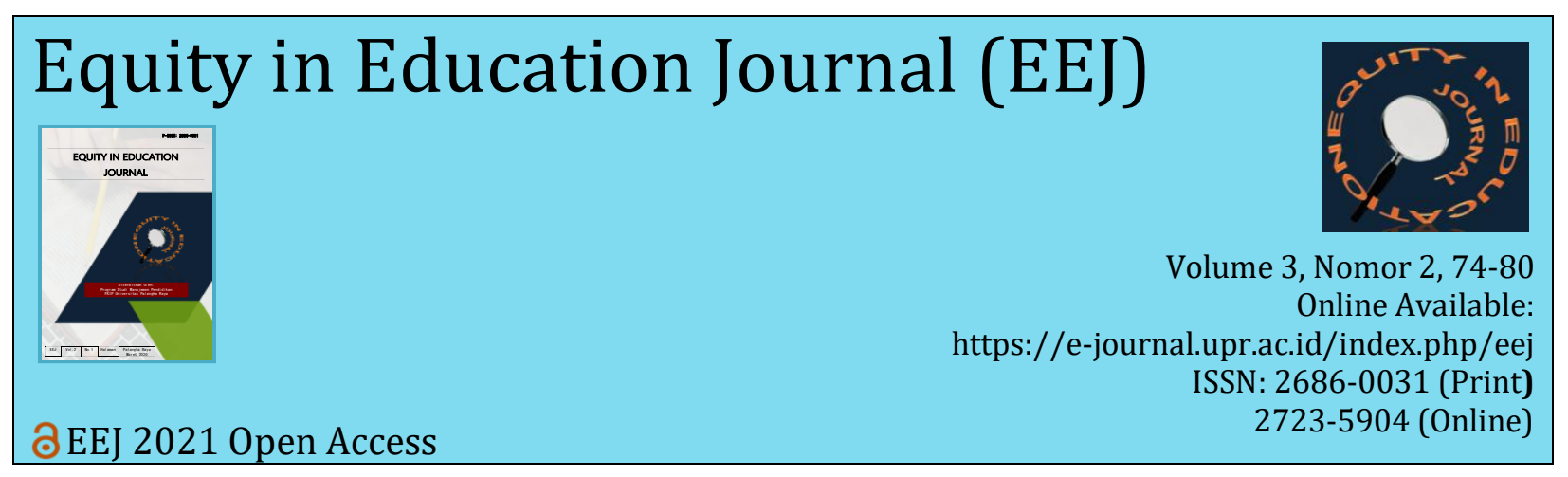

\title{
PENGARUH PELATIHAN TERHADAP KINERJA PEGAWAI LEMBAGA PENJAMINAN MUTU PENDIDIKAN (LPMP) PROVINSI KALIMANTAN TENGAH
}

\author{
Erfinna Lumban Gaol*, Piter Joko Nugroho, Chritian Radiafilsan \\ FKIP, Universitas Palangka Raya, Palangka Raya
}

\begin{tabular}{|c|c|}
\hline Info Artikel & Abstrak \\
\hline Riwayat Artikel: & $\begin{array}{l}\text { Penelitian ini bertujuan untuk mengetahui pengaruh pelatihan terhadap kinerja } \\
\text { pegawai pada Lembaga Penjaminan Mutu Pendidikan (LPMP) Provinsi Kalimantan }\end{array}$ \\
\hline Diterima: 29 April 2021 & Tengah. Populasi dalam penelitian ini adalah pegawai PNS di lingkungan LPMP \\
\hline Direvisi: 27 Juli 2021 & Provinsi Kalimantan Tengah sejumlah 89 orang. Penetapan sampel penelitian \\
\hline Disetujui: 4 Agustus 2021 & $\begin{array}{l}\text { menggunakan teknik rumus Slovin dan Umar selanjutnya ditetapkan sampel } \\
\text { sejumlah } 47 \text { orang. Teknik pengumpulan data dalam penelitian menggunakan angket }\end{array}$ \\
\hline Kata Kunci: & (kuesioner). Data diolah dan dianalisis menggunakan analisis regresi linier sederhana \\
\hline Pelatihan, Kinerja & menggunakan SPSS 17. Hasil penelitian menunjukkan bahwa pelatihan berpengaruh \\
\hline Pegawai, LPMP Provinsi & positif dan signifikan terhadap kinerja pegawai LPMP Provinsi Kalimantan Tengah. \\
\hline Kalimantan Tengah. & $\begin{array}{l}\text { Pengaruh variabel pelatihan terhadap variabel kinerja pegawai adalah sebesar } 45,6 \% \text {; } \\
\text { sedangkan sisanya } 54,4 \% \text { dipengaruhi oleh variabel lain yang tidak diteliti. }\end{array}$ \\
\hline Korespondensi: & Abstract \\
\hline Erfinna Lumban Gaol* & This study aims to determine the effect of training on employee performance at the \\
\hline FKIP, Universitas & Education Quality Assurance Institute (LPMP) of Central Kalimantan Province. The \\
\hline Palangka Raya & population in this study were civil servants in the LPMP of Central Kalimantan \\
\hline E-mail: & Province as many as 89 employees. The research sample was determined using the \\
\hline erfinnagaol@gmail.com & Slovin and Umar formula technique, then a sample of 47 people was determined. \\
\hline & $\begin{array}{l}\text { Data collection techniques in research using a questionnaire. The data were processed } \\
\text { and analyzed using simple linear regression analysis using SPSS } 17 \text {. The results } \\
\text { showed that training had a positive and significant effect on the performance of } \\
\text { LPMP of Central Kalimantan Province employees. The effect of training variables }\end{array}$ \\
\hline (c) & $\begin{array}{l}\text { on employee performance variables is } 45.6 \% \text {; while the remaining } 54.4 \% \text { is } \\
\text { influenced by other variables not examined. }\end{array}$ \\
\hline
\end{tabular}

\section{PENDAHULUAN}

Perkembangan teknologi yang semakin maju dari masa ke masa, membuat persaingan dalam dunia pekerjaan semakin meningkat, pekerjaan seseorang juga sangat menentukan pendidikan yang dimiliki. Pendidikan tidak dapat dipisahkan dengan pembangunan manusia yang seutuhnya, karena manusia jugalah yang mempertimbangkan tujuan akhir semua usaha pembangunan, baik sebagai perseorangan maupun sebagai anggota masyarakat (Kamrida \& Nasrullah, 2016). Manusia harus menjadi perhatian dan disiapkan untuk dapat melaksanakan berbagai macam tugas dan tanggung jawab yang akan diembannya, sehingga setiap lembaga atau instansi dituntut untuk memiliki sumber daya manusia yang mempunyai kinerja yang tinggi agar 
dapat membangun suatu lembaga atau instansi kearah yang lebih baik. Tika (2012) menyatakan kinerja sebagai hasil-hasil fungsi pekerjaan/kegiatan seseorang atau kelompok dalam suatu organisasi yang dipengaruhi oleh berbagai faktor untuk mencapai tujuan organisasi dalam periode waktu tertentu. Kinerja pegawai merupakan salah satu tolak ukur dari keberhasilan suatu instansi atau lembaga, dan demi tercapainya suatu tujuan instansi atau lembaga yang optimal, dibutuhkan kemampuan dari pucuk pimpinan untuk memperhatikan kecakapan hubungan antara staf/pegawai yang tentunya mengarah pada pembinaan dan pemberian motivasi kepada pegawai, sehingga pegawai dapat pula memahami tugas dan tanggung jawab masing-masing serta mematuhi aturan-aturan yang telah ditetapkan dalam instansi atau lembaga tersebut. Manusia yang ada dalam organisasi harus diatur karena baik atau buruknya sebuah organisasi tergantung pada sumber daya manusia yang menjalankannya.

Lembaga Penjaminan Mutu Pendidikan (LPMP) Provinsi Kalimantan Tengah adalah salah satu unit pelaksana teknis Kementerian Pendidikan dan Kebudayaan yang berada di bawah dan bertanggung jawab kepada Direktur Jenderal PAUD Dikdas dan Dikmen dan mempunyai tugas melaksanakan penjaminan mutu, pengembangan model dan kemitraan penjaminan mutu pendidikan dasar dan pendidikan menengah di provinsi berdasarkan kebijakan Menteri Pendidikan dan Kebudayaan. Sebagai perwakilan pusat di daerah, LPMP Provinsi Kalimantan Tengah berfokus pada penjaminan mutu pendidikan khususnya dalam mengawal pencapaian 8 (delapan) Standar Nasional Pendidikan (SNP) serta memiliki kewajiban dalam mengawal seluruh kebijakan pemerintah pusat yang direpresentasikan oleh Kementerian Pendidikan dan Kebudayaan (Kemdikbud) RI. Secara tegas dapat dinyatakan bahwa program dan kebijakan Kemdikbud seyogianya dikawal dan dilaksanakan secara efesien dan efektif oleh LPMP di tingkat daerah; sehingga menjadi suatu keniscayaan bagi LPMP untuk terus menerus meningkatkan kinerja institusinya untuk mewujudkan amanah tersebut dan dalam upaya tersebut tentu saja harus diimbangi pula dengan kinerja dari seluruh personilnya.

Tingkat kinerja pegawai pemerintahan dapat diukur/dilihat dengan mengacu pada Penilaian Prestasi Kerja (PPK) PNS sebagaimana diatur dalam Peraturan Pemerintah Nomor 30 Tahun 2019 tentang Penilaian Kinerja PNS. Dalam perundangan tersebut PPK PNS terdiri atas 2 (dua) unsur utama yaitu unsur Sasaran Kerja Pegawai (SKP) dengan bobot nilai 60\%, dan unsur Perilaku Kerja (PK) dengan bobot $40 \%$ yang meliputi aspek orientasi pelayanan, integritas, komitmen disiplin, kerjasama, serta kepemimpinan. Berdasarkan hasil studi awal yang dilakukan peneliti diketahui bahwa terdapat trend kinerja yang positif dari pegawai PNS di lingkungan LPMP Provinsi Kalimantan Tengah dalam 3 tahun terakhir (2018-2020) sebagaimana tersaji dalam Tabel 1.

Tabel 1. Data Perilaku Kinerja Pegawai LPMP Provinsi Kalimantan Tengah

\begin{tabular}{cccccc}
\hline No & Indikator & \multicolumn{3}{c}{ Nilai Kinerja/Tahun } & Keterangan \\
& & $\mathbf{2 0 1 8}$ & $\mathbf{2 0 1 9}$ & $\mathbf{2 0 2 0}$ & \\
\hline 1 & Orientasi pelayanan & 79 & 81 & 84 & Baik \\
2 & Integritas & 77 & 79 & 83 & Baik \\
3 & Komitmen & 78 & 80 & 83 & Baik \\
4 & Disiplin & 79 & 79 & 82 & Baik \\
5 & Kerja sama & 77 & 80 & 83 & Baik \\
\hline
\end{tabular}

(Sumber: LPMP Provinsi Kalimantan Tengah, 2020)

Mencermati data tersebut dapat dimaknai bahwa kinerja pegawai LPMP dalam 3 tahun terakhir menunjukkan hasil yang baik. Kinerja pegawai yang optimal salah satunya ditentukan oleh adanya pelatihan dan pengembangan yang terprogam dengan baik pula (Busono, 2016). Pendidikan dan pelatihan (diklat) merupakan salah satu faktor penting dalam pengembangan SDM. Diklat tidak hanya menambah pengetahuan, akan tetapi juga meningkatkan keterampilan bekerja, dengan demikian dapat meningkatkan kinerja (Sumarsono, 2009). Studi Dartha (2010) 
menyimpulkan pelatihan berpengaruh secara signifikan baik simultan maupun parsial terhadap kinerja pegawai negeri sipil. Pelatihan bagi pegawai merupakan hal yang sangat penting terutama untuk program pengembangan sumber daya manusia. Pelatihan dan pengembangan pegawai pada organisasi atau instansi pendidikan dilakukan untuk meningkatkan kualitas kinerja pegawai. Sehingga pelatihan pegawai dibutuhkan agar seluruh pegawai mampu mengikuti perkembangan dunia kerja sesuai dengan jabatannya. Pelatihan juga dilakukan sebagai cara meningkatkan produktivitas kerja, etos kerja, disiplin, sikap, keterampilan, dan keahlian tertentu agar bisa bekerja lebih maksimal serta lebih baik.

Berdasarkan uraian di atas, secara umum penelitian ini bertujuan untuk mengetahui pengaruh pelatihan terhadap kinerja pegawai PNS di lingkungan LPMP Provinsi Kalimantan Tengah mengunakan mengacu pada PPK PNS sebagai ukuran kinerja pegawai.

\section{METODE}

Penelitian ini menggunakan metode deskriptif analisis dengan pendekatan kuantitatif. Arikunto (2010) menyatakan metode kuantitatif adalah penelitian yang bertujuan untuk melihat pengaruh antara variabel yang ada berdasarkan perhitungan angka atau pengukuran data-data yang diperoleh dalam penelitian. Populasi dalam penelitian ini adalah pegawai PNS di lingkungan Lembaga Penjaminan Mutu Pendidikan Kalimantan Tengah sejumlah 89 orang yang selanjutnya menggunakan rumus Slovin ditetapkan sampel penelitian sejumlah 47 orang. Data kemudian diolah dan dianalisis menggunakan analisis regresi linier sederhana menggunakan SPSS 17.

\section{HASIL DAN PEMBAHASAN Uji Validitas}

Validitas merupakan derajat ketepatan antara data yang sesungguhnya terjadi pada objek penelitian dengan data yang dilaporkan oleh peneliti. Instrumen yang valid berarti alat ukur yang digunakan untuk mendapatkan data (mengukur) itu valid. Valid berarti instrumen tersebut dapat digunakan untuk mengukur apa yang seharusnya diukur (Sugiyono, 2017).

\begin{tabular}{cccc}
\multicolumn{4}{c}{ Tabel 2. Hasil Uji Validitas } \\
\hline No.Item & r hitung & $\begin{array}{c}\text { r } \\
\text { tabel }\end{array}$ & $\begin{array}{c}\text { Keteranga } \\
\text { n }\end{array}$ \\
\hline 1 & 0.728 & 0,444 & Valid \\
2 & 0.602 & 0,444 & Valid \\
3 & 0.481 & 0,444 & Valid \\
4 & 0.590 & 0,444 & Valid \\
5 & 0.445 & 0,444 & Valid \\
6 & 0.703 & 0,444 & Valid \\
7 & 0.531 & 0,444 & Valid \\
8 & 0.470 & 0,444 & Valid \\
9 & 0.604 & 0,444 & Valid \\
10 & 0.481 & 0,444 & Valid \\
11 & 0.534 & 0,444 & Valid \\
12 & 0.772 & 0,444 & Valid \\
13 & 0.649 & 0,444 & Valid \\
14 & 0.555 & 0,444 & Valid \\
15 & 0.535 & 0,444 & Valid \\
\hline
\end{tabular}

Berdasarkan sajian data dalam Tabel 2. di atas terkait uji validitas variabel pelatihan (X,) menujukkan bahwa nilai rtabel rata-ratanya memiliki nilai lebih besar dari rhitung, sehingga setiap butir instrumen layak di gunakan dalam melakukan penelitian. 
Sedangkan untuk validitas variabel Y dapat dilihat dari data dibawah ini:

Tabel 3. Hasil Uji Validitas Variabel Kinerja Pegawai (Y)

\begin{tabular}{cccc}
\hline No.Item & r hitung & r tabel & Keterangan \\
\hline 1 & 0.553 & 0.444 & Valid \\
2 & 0.526 & 0.444 & Valid \\
3. & 0.503 & 0.444 & Valid \\
4 & 0.663 & 0.444 & Valid \\
5 & 0.689 & 0.444 & Valid \\
6 & 0.867 & 0.444 & Valid \\
7 & 0.565 & 0.444 & Valid \\
8 & 0.702 & 0.444 & Valid \\
9 & 0.704 & 0.444 & Valid \\
10 & 0.624 & 0.444 & Valid \\
11 & 0.544 & 0.444 & Valid \\
12 & 0.550 & 0.444 & Valid \\
13 & 0.506 & 0.444 & Valid \\
14 & 0.643 & 0.444 & Valid \\
15 & 0.462 & 0.444 & Valid \\
16 & 0.765 & 0.444 & Valid \\
17 & 0.669 & 0.444 & Valid \\
\hline
\end{tabular}

Berdasarkan sajian data dalam Tabel 3. di atas menujukkan bahwa nilai rtabel rata-ratanya memiliki nilai lebih besar dari rhitung, sehingga setiap butir instrumen layak di gunakan dalam melakukan penelitian.

\section{Uji Reliabilitas}

Menurut Arikunto (2010) variabel dinyatakan reliable apabila nilai Alpha Cronbach minimal 0,6. Pengujian reliabilitas instrumen menggunakan rumus Alpha Cronbranch karena instrumen penelitian ini berbentuk angket. Suatu intrumen dikatakan reliabel apabila hasil pengukuran instrumen tersebut adalah sama jika sekiranya pengukuran tersebut dilakukan pada orang yang sama pada waktu yang berlainan (tetapi mempunyai kondisi yang sama) pada waktu yang sama atau pada waktu yang berlainan. Perhitungan reliabilitas instrumen dilakukan dengan bantuan program komputer yaitu: Statistical Product and Service Solution (SPSS) versi 17. Sujarweni (2014) menyatakan kuisioner dinyatakan reliabel jika Cronbach Alpha > 0,6. Berdasarkan hasil analisis dengan menggunakan program komputer yaitu Statistical Product and Service Solution (SPSS) versi 17 diperoleh hasil uji reliabilitas instrumen penelitian sebagai berikut:

Tabel 4. Hasil Uji Reliabilitas

\begin{tabular}{ccc}
\hline Variabel & Koefisien Alpha & Keterangan \\
\hline Pelatihan & 0.857 & Reliabel \\
Kinerja Pegawai & 0.899 & Reliabel \\
\hline
\end{tabular}

Berdasarkan nilai koefisien realibilitas (Alpha Cronbach) pengaruh pelatihan terhadap kinerja pegawai berdasarkan PPK sebesar 0.857 pada variabel X dan 0.899 pada variabel Y. Maka dari itu, dapat disimpulkan nilai Alpha tersebut termasuk ke dalam kriteria tingkat kepercayaan yang sangat tinggi dan sangat reliabel untuk digunakan dalam pengambilan data, karena berdasarkan nilai Alpha Cronbach > 0,6 yang berarti data penelitian dapat dikatakan reliable. 


\section{Uji Normalitas}

Uji Normalitas data yang dilakukan tiap masing-masing data dengan tujuan untuk mengetahui apakah data tersebut berasal dari populasi distribusi normal atau tidak. Untuk uji normalitas menggunakan one-sample kolmogorov-smirnov test pada program IBM SPSS Statistic 20 dengan taraf signifikasi $\alpha=0,05$.

Tabel 5. Hasil Uji Normalitas One Sample Kolmogorov-Smirnov Test

\begin{tabular}{llr}
\hline & & Unstandardized Residual \\
\hline $\mathrm{N}$ & & 47 \\
Normal & Mean &, 0000000 \\
Parameters ${ }^{\mathrm{a}, \mathrm{b}}$ & Std. & 4,38762508 \\
& Deviation & \\
Most Extreme & Absolute &, 119 \\
Differences & Positive &, 119 \\
& Negative &,- 092 \\
Kolmogorov-Smirnov Z &, 812 \\
Asymp. Sig. (2-tailed) &, 524 \\
\hline
\end{tabular}

Hasil penelitian dikatakan berdistribusi normal atau memenuhi uji normalitas apabila nilai Asymp. Sig (2-tailed) variabel residual berada diatas 0.05 atau 5\%. Sebalikmya apabila berada dibawah 0.05 atau $5 \%$ data tidak berdistribusi normal atau tidak memenuhi uji normalitas. Berdasarkan hasil uji normalitas diketahui nilai signifikansi $0.524>0.05$, maka dapat disimpulkan bahwa nilai residual berdistribusi normal. Dengan demikian, asumsi atau persyaratan normalitas dalam model regresi sederhana terpenuhi.

\section{Analisis Regresi}

Penelitian ini menggunakan uji analisis regresi linear sederhana untuk melihat seberapa besar pengaruh positif pelatihan terhadap kinerja pegawai PNS di LPMP Provinsi Kalimantan Tengah.

Tabel 6. Tabel Uji Regresi Linear Sederhana melalui program SPSS 17 Coefficients $^{\mathbf{a}}$

\begin{tabular}{|c|c|c|c|c|c|c|}
\hline & \multirow[t]{2}{*}{ Model } & \multicolumn{2}{|c|}{$\begin{array}{c}\text { Unstandardized } \\
\text { Coefficients }\end{array}$} & \multirow{2}{*}{$\begin{array}{c}\text { Standardized } \\
\text { Coefficients } \\
\text { Beta }\end{array}$} & \multirow[t]{2}{*}{$\mathbf{T}$} & \multirow[t]{2}{*}{ Sig. } \\
\hline & & B & $\begin{array}{l}\text { Std. } \\
\text { Error }\end{array}$ & & & \\
\hline \multirow[t]{2}{*}{1} & (Constant) & 17,626 & 7,195 & \multirow[b]{2}{*}{,675 } & 2.450 & $\overline{0}, 018$ \\
\hline & Pelatihan & ,838 & ,137 & & 6.139 & ,000 \\
\hline
\end{tabular}

Dari Tabel 6. di atas menunjukkan hasil yang diperoleh nilai constant (a) sebesar 17,626 sedangkan pelatihan (b/koefisien regresi) sebesar 0,838. Dari hasil tersebut dapat dimasukkan dalam persamaan regresi sebagai berikut:

$$
\begin{gathered}
Y=a+b X \\
Y=17,626+0,838 X
\end{gathered}
$$

Dari hasil persamaan di atas dapat diterjemahkan nilai konstanta (a) sebesar 17,626 yang mengandung arti jika pelatihan nilainya adalah 0 , maka nilai konsistensi dari variabel kinerja pegawai (Y) adalah 17,626. Kemudian nilai regresi variabel pelatihan (b) adalah 0,838 ini dapat 
diartikan bahwa setiap peningkatan pelatihan sebesar $1 \%$ maka tingkat kinerja pegawai juga akan meningkat sebanyak $83,8 \%$. Dari data tersebut dapat dilihat jika koefisien regresi tersebut bernilai positif, sehingga dapat dikatakan bahwa arah pengaruh pelatihan (variabel X) terhadap kinerja pegawai (variabel Y) adalah positif. Berdasarkan nilai signifikansi yang diperoleh dari Tabel 6. diatas yaitu sebesar $0,000<0,05$, sehingga dapat disimpulkan bahwa variabel pelatihan (X) berpengaruh terhadap variabel kinerja pegawai PNS (Y) di LPMP Provinsi Kalimantan Tengah.

\section{Uji Hipotesis}

Tabel 7. Hasil Uji t

Coefficients ${ }^{\mathbf{a}}$

\begin{tabular}{|c|c|c|c|c|c|c|}
\hline & \multirow[b]{2}{*}{ Model } & \multicolumn{2}{|c|}{$\begin{array}{c}\text { Unstandardized } \\
\text { Coefficients }\end{array}$} & \multirow{2}{*}{$\begin{array}{c}\begin{array}{c}\text { Standardized } \\
\text { Coefficients }\end{array} \\
\text { Beta }\end{array}$} & \multirow[b]{2}{*}{$\mathbf{T}$} & \multirow[b]{2}{*}{ Sig. } \\
\hline & & B & $\begin{array}{l}\text { Std. } \\
\text { Error }\end{array}$ & & & \\
\hline \multirow[t]{2}{*}{1} & (Constant) & 17,626 & 7,195 & & 2.450 & ,018 \\
\hline & Pelatihan & ,838 & ,137 & 675 & 6.139 & ,000 \\
\hline
\end{tabular}

Berdasarkan sajian data dalam Tabel 7. di atas, diketahui hasil regresi diperoleh nilai thitung sebesar 6,139 dengan koefisien regresi sebesar 0,838 dan $\alpha=5 \%(0,05)$. Artinya thitung $=6,139$ lebih besar dari nilai tabel $(0,05: 45)=1,679$ dengan nilai sigifikansi $0,00<0,05$. Dapat diambil kesimpulan bahwa dengan adanya pelatihan berpengaruh positif dan signifikan terhadap kinerja pegawai karena nilai thitung > ttabel dan nilai signifikan lebih kecil dari 0,05 sehingga Ho ditolak dan Ha diterima. Dalam hal ini menunjukkan bahwa dengan adanya pelatihan yang diberikan kepada pegawai PNS memiliki pengaruh positif dan signifikan terhadap kinerja pegawai di lingkungan LPMP Provinsi Kalimantan Tengah.

\section{Uji Koefisien Determinasi}

Tabel 8. Hasil Koefisien Determinasi $\mathbf{R}^{2}$ Model Summary

\begin{tabular}{ccccc}
\hline Model & R & R Square & $\begin{array}{c}\text { Adjusted } \\
\text { Square }\end{array}$ & $\begin{array}{c}\text { R } \\
\text { Std. Error of } \\
\text { the Estimate }\end{array}$ \\
\hline 1 & $.675^{\text {a }}$ & .456 & .444 & 4.436 \\
\hline
\end{tabular}

Berdasarkan sajian data dalam Tabel 8. di atas dapat disimpulkan bahwa koefisien determinasi ( $R$ Square) sebesar 0,456 yang mengandung pengertian bahwa pengaruh variabel pelatihan terhadap variabel kinerja pegawai adalah $45,6 \%$, sedangkan sisanya $54,4 \%$ dipengaruhi oleh variabel yang tidak diteliti.

Temuan penelitian yang mengungkap faktor pelatihan berpengaruh secara positif dan signifikan terhadap peningkatan kinerja pegawai ASN di lingkungan LPM Provinsi Kalimantan Tengah ini semakin menegaskan pentingnya pembinaan dan pengembangan Sumber Daya Manusia (SDM) melalui pelatihan pada berbagai institusi pemerintahan dalam upaya meningkatan kinerja organisasi melalui peningkatan kinerja SDMnya. Pencapaian tujuan organisasi tergantung pada kinerja pegawainya. Pegawai yang terlatih hingga lebih terampil terhadap pekerjaannya akan lebih percaya diri dan merasa lebih berguna bagi pemerintah (Handoko, 2009). Pegawai yang mendapatkan program pengembangan profesional melalui pelatihan akan menjadi semakin profesional dalam melaksanakan tugas yang diberikan kepadanya. Oleh karenanya jika sebuah lembaga menginginkan keunggulan bersaing melalui SDM harus memuat konsep pelatihan dan pengembangan SDM secara kontinyu karena melalui 
pelatihan dan pengembangan tersebut akan menjadikan organisasi/lembaga menjadi lebih efektif (Devi \& Shaik, 2012).

\section{SIMPULAN}

Berdasarkan hasil penelitian dan pembahasan dapat disimpulkan bahwa pelatihan berpengaruh secara positif dan signifikan terhadap kinerja pegawai PNS di lingkungan LPMP Provinsi Kalimantan Tengah dengan nilai pengaruh dari Standardized Coefficients=17,626 dan nilai signifikansi sebesar $0,000<0,05$, maka Ho ditolak dan Ha diterima. Pelatihan yang dilaksanakan secara terprogram bagi pegawai ASN di LPMP Provinsi Kalimantan Tengah berdampak pada peningkatan kinerja pegawainya. Secara simultan pelatihan berpengaruh positif dan signifikan terhadap kinerja pegawai PNS di lingkungan LPMP Provinsi Kalimantan Tengah dengan pengaruh sebesar $45,6 \%$, sisanya sebesar 54,4\% merupakan pengaruh dari variabel lain yang tidak diteliti.

\section{UCAPAN TERIMA KASIH}

Ucapan terima kasih penulis sampaikan kepada pihak Lembaga Penjaminan Mutu Pendidikan (LPMP) Provinsi Kalimantan Tengah yang telah banyak membantu dan mengijinkan untuk melakukan penelitian di lembaga tersebut, serta redaksi Equity in Education Journal (EEJ) yang telah memberikan kesempatan artikel penulis dapat dimuat dalam jurnal ini.

\section{DAFTAR PUSTAKA}

Arikunto, S. (2010). Prosedur Penelitian: Suatu Pendekatan Praktik. Jakarta : Rineka Cipta.

Busono, G. A. (2016). Pengaruh Sistem Pelatihan dan Pengembangan Karyawan terhadap Kinerja Karyawan PT. Persada Sawit Mas (PSM) Kecamatan Pampangan Kabupaten Ogan Komering Ilir. Muqtashid, 1(1).

Dartha, I. K. (2010). Pengaruh Pendidikan dan Pelatihan (Diklat) terhadap Kinerja Pegawai Negeri Sipil pada Sekretariat Daerah Kota Malang. Jurnal Ekonomi Modernisasi, 6(2).

Devi, V. R., \& Shaik, N. (2012). Training \& Development-A Jump Starter for Employee Performance and Organizational Effectiveness. International Journal of Social Science \& Interdisciplinary Research, 1(7).

Handoko, T. H. (2009). Manajemen. Yogyakarta: Penerbit BPEE.

Kamrida, A., \& Nasrullah, M. (2016). Pengaruh Pendidikan dan Pelatihan terhadap Kinerja Pegawai pada Kantor Lembaga Penjaminan Mutu Pendidikan Provinsi Sulawesi Selatan. Jurnal Office, 2(2).

LPMP Provinsi Kalimantan Tengah. (2020). Data Penilaian Perilaku Kerja Tahun 2020. Palangka Raya: Lembaga Penjaminan Mutu Pendidikan (LPMP) Provinsi Kalimantan Tengah.

Peraturan Pemerintah Nomor 30 Tahun 2019 tentang Penilaian Kinerja PNS.

Sugiyono. (2017). Metode Penelitian Pendidikan Pendekatan Kuantitatif, Kualitatif. Jakarta: Alfabeta.

Sujarweni, V. W. (2014). Metode Penelitian: Lengkap, Praktis, dan Mudah Dipahami. Yogyakarta: Pustaka Baru Press.

Sumarsono. (2009). Ekonomi SDM dan Teori dan Kebijakan Publik. Yogyakarta: Graha Ilmu.

Tika. (2012). Budaya Organisasi dan Peningkatan Kinerja Perusahaan. Jakarta: Bumi Aksara. 